\title{
The influence of transformational leadership on Malaysian students' entrepreneurial behaviour
}

\author{
Muhammad Ashraf Fauzi, Tulasi Martin, Kamalesh Ravesangar
}

\begin{abstract}
A B S T R A C T
Objective: The objective of the article is to understand entrepreneurial abilities of students in Malaysian higher education system. Hence, the role of transformational leadership, psychological empowerment, and knowledge sharing in inducing this behaviour are imperative to ensure that students are inclined to and familiar with entrepreneurial activities during their studies.

Research Design \& Methods: This research focused on Malaysian undergraduate students' entrepreneurial behaviour and related antecedents. A group of 177 undergraduate students from various engineering programs was collected. A partial least square structural equation modelling (PLS-SEM) was conducted to analyse the relationship between entrepreneurial behaviour and related antecedents.

Findings: The results show that among the four transformational factors, inspirational motivation is deemed to be the strongest predictor of both knowledge sharing and entrepreneurial behaviour. This is followed by an individualised consideration which tracks full significant impact and partial impact on knowledge sharing and entrepreneurial behaviour. On the other hand, idealised influence and intellectual stimulation show no effect, while psychological empowerment and knowledge sharing show a significant impact on entrepreneurial behaviour.

Implications \& Recommendations: The outcomes of this study would benefit stakeholders in implementing entrepreneurial activities and foster successful implementation in the curriculum of the Malaysian higher education system.

Contribution \& Value Added: This study contributes to the body of knowledge in the relationship of knowledge sharing, transformational leadership style, and entrepreneurial behaviour of students in Malaysian higher education institutions.

\begin{tabular}{lll}
\hline Article type: & research article & \\
Keywords: & transformational leadership; psychological empowerment; knowledge sharing; entre- \\
JEL codes: & preneurial behaviour; higher education & \\
\hline \multicolumn{1}{c}{ Received: 13 May 2020 } & Revised: 15 November 2020 & Accepted: 22 November 2020 \\
\hline
\end{tabular}
\end{abstract}

\section{Suggested citation:}

Fauzi, M.A., Martin, T., \& Ravesangar, K. (2021). The influence of transformational leadership on Malaysian students' entrepreneurial behaviour. Entrepreneurial Business and Economics Review, 9(1), 89-103. https://doi.org/10.15678/EBER.2021.090106

\section{INTRODUCTION}

Reduced job offers and an overabundance of graduate students every year led to global unemployment problems (Pittaway \& Cope, 2007). The issue poses a domino effect that may lead to other socioeconomic issues in the community, especially among the youth, unless we introduce preventive measures and solutions. Hence, many higher education institutions now offer courses in entrepreneurship to equip potential individuals to become owner of their own businesses rather than becoming conventional workers (Martin, McNally, \& Kay, 2013). This issue is relatively important as the world moves forward, while traditional jobs for which one applies and waits for interviews may one day become irrelevant. Thus, the burden and task of equipping students with the right abilities became universities' major concerns and responsibilities. In this regard, universities can offer entrepreneurship 
courses or make them compulsory requirements for graduation. Despite the importance of entrepreneurial curriculum in universities, there has been no in-depth study to study the critical factors that can facilitate and enhance entrepreneurship behaviour and abilities of students in universities.

In terms of leadership practice, transformational leadership is known to be positively related to various stimulations of positive behaviour (Lan \& Chong, 2015). Transformational leadership theory first emerged in Western countries, with its most notable model being the Multi-factor Leadership Questionnaire (MLQ; Avolio, Bass, \& Jung, 1999). The earliest systematic study on transformational leadership was made by Bass (1985) who scrutinized the four dimensions of transformational leadership. This theoretical formulation of transformational leadership was established as the basis for interpersonal behaviour (Salamzadeh, 2020).

The four dimensions are (1) inspirational motivation, namely the level of inspirational vision from leaders towards followers, by optimistically communicating about future goals and vision and equipping reasonable meaning to current tasks; (2) individualised consideration, meaning a leader who acts as a mentor or personal coach assists in tasks appointed to the follower; (3) intellectual stimulation, in which the leader empowers, encourages, and stimulates activities, while followers fulfil tasks; (4) idealised influence, that is the charisma possessed by leaders that can emphasise the importance of purpose, commitment, and the result of a decision from an ethical perspective (Li, Zhao, \& Begley, 2015).

Leadership style is an essential variable with a significant impact on knowledge sharing (KS) innovation. After all, leadership facilitates organisations to share, integrate, and practically use knowledge for their development and benefits (Liu \& DeFrank, 2013; Mushtaq \& Bokhari, 2011). Scholars especially consider the two most influential leadership styles: transformational and transactional (Masa'deh, Obeidat, \& Tarhini, 2016). Transactional leadership is better in predicting task performance of individuals as prescribed by task and role, while transformational leadership is better in predicting contextual performance (Wang, Tsui, \& Xin, 2011; Baytok, Kurt, \& Zorlu, 2014). Both styles promote self-efficiency but contrast with the method of motivation and the way to achieve goals in organisations (Tyssen, Wald, \& Spieth, 2014). As the literature indicates, transformational leadership can better improve discretionary behaviours and innovativeness as compared to transactional leadership (Nam Nguyen \& Mohamed, 2011; Wang et al., 2011). Others find that the former better influences organisational performance than the latter (Birasnav, 2014). Hence, this study is formulated by incorporating the transformational style and critical component of knowledge sharing, along with psychological empowerment infused within organisations.

This study will empirically show how subordinates are indirectly inspired when achieving the highest levels of excellence by doing extra work effort rather than only completing assigned duties by superior, contributed by the transformational leadership style (Afsar, Badir, Saeed, \& Hafeez, 2016). Through the four dimensions of transformational leadership (idealised influence, inspirational motivation, intellectual stimulation and individualised consideration) this study will reveal and discern the important of transformational leadership together with psychological empowerment and knowledge sharing towards entrepreneurship behaviour.

\section{LITERATURE REVIEW AND HYPOTHESIS DEVELOPMENT}

\section{Entrepreneurial behaviour}

Entrepreneurial skills of individuals should be developed when they are young, and university can be regarded as the best setting for these particular skills to be nourished. Honing students' entrepreneurial skills is a very difficult task on its own. Hence, it must be supported by other critical components that can be infused within campus life. With entrepreneurial activities supported by the university, there are several vital components of factors that can play a part in realising this, such as leadership styles (Jauhari, Singh, \& Kumar, 2017; Han, Seo, Yoon, \& Yoon, 2016), psychological empowerment (Coun, Peters, \& Blomme, 2018; Farrukh, Lee, \& Shahzad, 2019), and knowledge sharing (De Clercq, Dimov, \& Thongpapanl, 2013; Hormiga, de Saa-Perez, \& Diaz-Diaz, 2016). 


\section{Transformational leadership}

Transformational leadership is defined as a leadership style that transforms followers to value the group over self-interest based on their ideals and morale by motivating them to perform better than expected (Bass, 1985; Zbierowski, 2016). In contrast, transactional leadership is based on an exchange relationship between a leader and followers in which the leader prepares predefined goals that followers must achieve (Pieterse, Van Knippenberg, Schippers, \& Stam, 2010). The four dimensions of transformational leadership are idealised influence, inspirational motivation, intellectual stimulation, and individualised consideration (Bass \& Avolio, 1994).

This study is based on antecedents of transformational leadership from endogenous variables of psychological empowerment, knowledge sharing, and entrepreneurial behaviour. We propose 11 hypotheses to understand the relationship between these variables.

Idealised influence. Idealised influence is known as the leader's charisma (Giltinane, 2013). The term "charisma" was used in early studies of transformational leadership but was then changed to "idealised influence" as the original notion appeared incompatible with transformational ideas (Barbuto, 2005). This charismatic feature forms an attraction of followers through an emotional bond created by which the idealised behaviour of the leader forms collective organisation values translated into actions. Leaders high in idealised influence are to be role models, focused on, oriented towards, and persistent in achieving targeted goals (Gabel, 2012). In achieving the vision, followers would show dedication and commitment based on the influence of the leader's charisma.

H1: Individualised consideration will have a positive impact on students' knowledge sharing behaviour.

H2: Individualised consideration will have a positive impact on students' entrepreneurial behaviour.

Inspirational motivation. In ensuring followers to perform their best in completing a certain task, a leader can motivate their followers by inspiration and motivation (Long, Yusof, Kowang, \& Heng, 2014). Leaders spread their message by inspiring and stimulating a sense of belief and bestowing challenges in achieving organisation goals and targets. By this, team spirit is harnessed with the belief of followers, which result in the followers showing eagerness and positive thinking. Leaders with high inspirational motivation can motivate followers beyond their expectation (Mittal \& Dhar, 2015). Together with idealised influence, inspirational leaders are largely influenced by emotions (Deinert, Homan, Boer, Voelpel, \& Gutermann, 2015).

H3: Inspirational motivation will have a positive impact on students' knowledge sharing behaviour.

H4: Inspirational motivation will have a positive impact on students' entrepreneurial behaviour.

Intellectual stimulation. Intellectual stimulation is a form of motivating behaviour that provides followers with meaning in doing their task, which transforms into fostering optimism through leader behaviour. Thus, followers will be inspired through the leader's symbolic actions (Deinert et al., 2015). Leaders that can stimulate the intellect of subordinates can increase their interest in problem-solving, along with ability and competence to think in new and creative ways (Carreiro \& Oliveira, 2019). Leaders can empower their followers by strengthening their willpower and confidence, which would ignite the followers' cognitive capability in solving problems creatively (Al-Husseini \& Elbeltagi, 2018). Followers would avail themselves to discuss their problems openly and disclose matters pertaining work, which may be perceived as critical and essential to an organisation's growth.

H5: Intellectual stimulation will have a positive impact on students' knowledge sharing behaviour.

H6: Intellectual stimulation will have a positive impact on students' entrepreneurial behaviour.

Individualised consideration. Transformational leaders treat individuals on a one-to-one basis, that is as individuals and not as replaceable components in a machines. The leader's personalised attention 
will show appreciation and acknowledgment towards the followers. By individualised consideration, leaders connect with followers to form a bond of relationship (Martin, 2017). Individual goals and needs are made to know and work together to achieve subordinates' career objectives. The individualised consideration of leaders promotes the sharing of power and induces subordinates to express positive belief in upholding their abilities, proactive encouragement, and developing good behaviours (Chen, Davison, Mao, \& Wang, 2018). Similar to intellectual stimulation, leaders who can focus on individual followers would achieve an emotional bond that can encourage followers to live up to their potential, which can in return benefit the organisation.

H7: Individualised consideration will have a positive impact on students' knowledge sharing behaviour.

H8: Individualised consideration will have a positive impact on students' entrepreneurial behaviour.

\section{Knowledge sharing}

Knowledge sharing has been the peak achievement in the field of knowledge management (Fauzi, Tan, \& Thurasamay, 2018b). Studies show that knowledge sharing is an important aspect that motivates individuals to enhance entrepreneurial behaviour (Hormiga et al., 2016; De Clercq et al., 2013; Castro, Nagano, \& Ribeiro, 2019). Many argue that knowledge sharing should be practiced and developed into a culture and norm in higher education as it is the place where knowledge is disseminated and celebrated (Fauzi, Tan, Thurasamy, \& Ojo, 2019c). All the four variables of transformational leadership are predicted to have positive significant impact on knowledge sharing. Hence, we describe the four variables below.

\section{Psychological empowerment}

Psychological empowerment is defined as motivation that is experienced by an individual based on his or her work role (Spreitzer, 1995). Psychological empowerment is primarily identified by subordinate's autonomous motivation, i.e. the perception of meaning, self-determination, competence, and impact (Sun, Zhang, Qi, \& Chen, 2012). A person with a high level of empowerment would perform more than required and beyond expectations (Spreitzer, 2008). Psychological empowerment is a distinct characteristic of internal motivation. This is because psychological empowerment is driven by active motivation from the individual self, unlike general intrinsic motivations that are passive (Kang, Lee, \& Kim, 2017). The internal motivation from the enactment of psychologically empowered persons is required when one must deal with entrepreneurial activities.

Scholars categorise psychological empowerment into four domains: 1 ) meaning (fitting one's belief system and goals to a task requirement), 2) competence (capability in performing the task), 3) impact (ownership and personal influence on the outcome of a group's work), and 4) self-determination (the sense of looking through task processes and actions; Houghton, Pearce, Manz, Courtright, \& Stewart, 2015). Recent studies find through meta-analyses that these four domains represent an active motivation to an individual's work relationship (Seibert, Wang, \& Courtright, 2011; Zhu, Sosik, Riggio, \& Yang, 2012). There appeared various studies on psychological empowerment in the workplace (Cicolini, Comparcini, \& Simonetti, 2014) that show a strong supportive empirical evidence of its importance in the study of human behaviour. Hence, psychological empowerment is expected to have a positive influence on knowledge sharing and entrepreneurial behaviour respectively, which we indicate in the below hypotheses:

H9: Psychological empowerment will have a positive impact on student's knowledge sharing behaviour.

H10: Psychological empowerment will have a positive impact on student's entrepreneurial behaviour.

Similarly, knowledge sharing would entail a positive influence on entrepreneurial behaviour, as we posit:

H11: Knowledge sharing will have a positive impact on student's entrepreneurial behaviour. 
The research model with the exogenous and endogenous variables form the 11 hypotheses, as shown in Figure 1 below.

H11

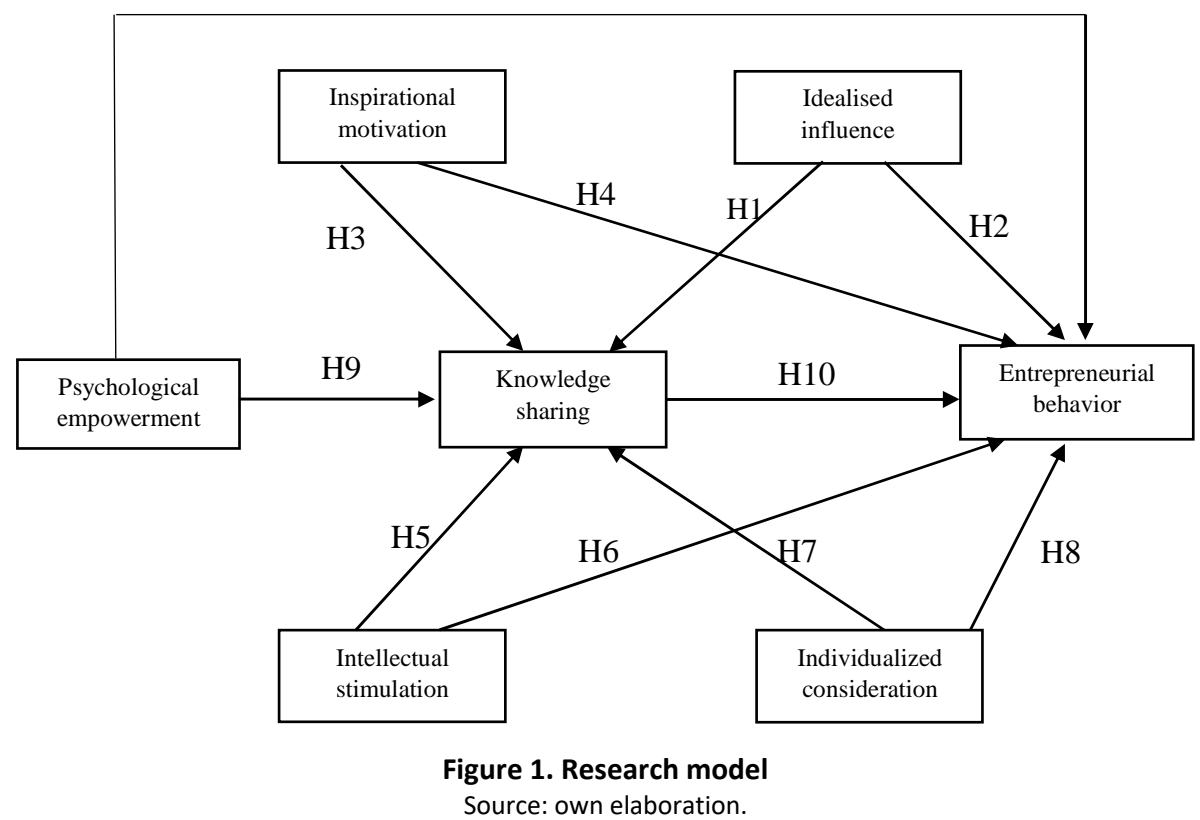

\section{RESEARCH METHODOLOGY}

This study is based on a self-administered survey sent to undergraduate engineering students in a public university in Malaysia. We decided on the quota non-random sampling method in choosing an equal portion of engineering students. In analysing the relationship between the variables, we applied SmartPLS 3.2. Partial least square structural equation modelling was suitable in testing the relationship as this study is considered to be explorative (Henseler, Ringle, \& Sarstedt, 2015).

\section{Item development}

The questionnaire used in this study was adapted from previously validated studies. In distributing the questionnaire, items from validated studies required us to ensure that the validity of the items was proven. However, some of the wordings were changed to suit the context of the current study. In ensuring the survey questions are suitable and understandable by potential respondents, it was sent to two expert reviewers in accomplishing face validity and content validity of the instrument.

Transformational leadership. The 20 items of transformational leadership were adapted from Bass and Avolio (1995) on the MLQ multifactor leadership questionnaire. Each of the items was divided into the four components of transformational leadership. Students were instructed to answer the questionnaire based on a seven-point Likert scale ranging from 1 (strongly disagree) to 7 (strongly agree). The sample items for idealised influence were "My leader instils pride in me when associated with others" and "My leader talks about my most important values and beliefs." Sample items for inspirational motivation were "My leader considers moral and ethical consequences of decisions" and "My leader displays a sense of power and confidence." Sample items for intellectual stimulation were "My leader articulates a compelling vision of future" and "My leader seeks differing perspectives when solving problems." Sample items for individualised consideration were "My leader spends time coaching, teaching, and mentoring his/her followers" and "My leader treats others as individuals rather than just as a member of a group."

Psychological empowerment. The eight items for psychological empowerment were adapted from Spreitzer (1995). Even though psychological empowerment is divided into four aspects - meaning, 
competence, self-determination, and impact - this study aims to examine psychological empowerment as a single variable. The relationship between the four components of transformational leadership was designed as the required relationship to be studied within the current context that consists of a seven-point Likert scale ranging from 1 (strongly disagree) to 7 (strongly agree). The sample item included was "I have considerable opportunity for independence and freedom in how I do my job."

Knowledge sharing. The six items of knowledge sharing were originally adapted from Akhavan, Hosseini, Abbasi, and Manteghi (2015). To suit the current context of the Malaysian higher education system, the most current version of items for knowledge sharing were taken from Fauzi et al. (2018a) and Fauzi, Tan, Thurasamy Ojo, and Shogar (2019b). The sample items included were "I share my knowledge and experience with my friends" and "I share the results of my activities with my friends." A seven-point Likert scale was adopted, ranging from 1 (strongly disagree) to 7 (strongly agree).

Entrepreneurial behaviour. The nine items of entrepreneurial behaviour were adapted from Afsar et al. (2016). The items were arranged on a seven-point Likert scale ranging from 1 (strongly disagree) to 7 (strongly agree). The sample items included were "This university displays an enthusiasm for acquiring new skills" and "This university quickly changes course of action when results are not achieved."

\section{RESULTS AND DISCUSSION}

The demographic data are shown in Table 1. The percentage of male and female students is $59.32 \%$ and $40.68 \%$, respectively. As for nationality, Malay students top the list with $84.75 \%$, followed by Chinese with $7.91 \%$, and Indian with $1.69 \%$. The number of Malay students is usually higher than other nationalities in Malaysian public higher education institutions because of their mostly low socioeconomic background, which depends on the enrolments in public higher education institutions, which result in the high number of Malay students. All the students are studied engineering, specialising in different majors: electrical (31.64\%), mechanical (27.12\%), manufacturing (24.29\%), and technology (16.95\%).

Table 1. Demographic information

\begin{tabular}{|l|c|c|c|}
\hline \multirow{3}{*}{ Measure } & Items & Frequency & Percentage \\
\hline \multirow{3}{*}{ Gender } & Male & 105 & 59.32 \\
\hline \multirow{4}{*}{ Race } & Female & 72 & 40.68 \\
\cline { 2 - 4 } & Malay & 150 & 84.75 \\
\hline \multirow{4}{*}{ Major } & Chinese & 14 & 7.91 \\
\cline { 2 - 4 } & Indian & 3 & 1.69 \\
\cline { 2 - 4 } & Others & 10 & 5.65 \\
\cline { 2 - 4 } & Electrical & 56 & 31.64 \\
\cline { 2 - 4 } & Mechanical & 48 & 27.12 \\
\cline { 2 - 4 } & Manufacturing & 43 & 24.29 \\
\cline { 2 - 4 } & Technology & 30 & 16.95 \\
\hline
\end{tabular}

Source: own study.

\section{Measurement model}

In the first stage of assessment with the PLS-SEM method, we computed a measurement model. The internal consistency reliability for this study was established by measuring the composite reliability, instead of Cronbach Alpha. The composite reliability was more appropriate as it weighs in the indicator differential weights (Djikstra \& Henseler, 2015) as opposed to Cronbach's alpha that takes into account the equal indicator of tau-equivalence. As for convergent validity, it was determined by the value of the outer loadings (should be more than 0.708 ) for the average variance extracted (AVE) to achieve at least $50 \%$ of the variance (Hair, Matthews, Matthews, \& Sarstedt, 2017).

Convergent validity. In assessing convergent validity, the outer loading of each item was computed using the PLS algorithm function. Items below 0.70 were deleted (Hair et al., 2014). The deleted items were IC3, PE7, PE8, EB2, and KS4, which amounted to five items. The value of composite reliability and average variance extracted of all constructs had at least 0.800 and 0.500 , respectively, 
as required (Hair, Hult, Ringle, \& Sarstedt, 2014). The results of internal consistency and convergent validity are shown in Table 2 below.

Table 2. Internal consistency and convergent validity

\begin{tabular}{|l|c|c|c|}
\hline \multicolumn{1}{|c|}{ Variable } & Cronbach's Alpha & $\begin{array}{c}\text { Composite } \\
\text { Reliability }\end{array}$ & $\begin{array}{c}\text { Average Variance } \\
\text { Extracted (AVE) }\end{array}$ \\
\hline Entrepreneurial behaviour (EB) & 0.911 & 0.928 & 0.618 \\
\hline Idealised influence (II) & 0.861 & 0.899 & 0.642 \\
\hline Individualised consideration (IC) & 0.812 & 0.876 & 0.64 \\
\hline Inspirational motivation (IM) & 0.864 & 0.902 & 0.649 \\
\hline Intellectual stimulation (IS) & 0.851 & 0.894 & 0.627 \\
\hline Knowledge sharing (KS) & 0.838 & 0.891 & 0.672 \\
\hline Psychological empowerment (PE) & 0.883 & 0.911 & 0.632 \\
\hline
\end{tabular}

Source: own study.

Discriminant Validity. The discriminant validity was tested with the Fornell-Larcker and Heterotrait-Monotrait ration of correlation criterions (HTMT), as suggested by Henseler et al. (2015). Three values were found to exceed the threshold of HTMT0.90, as recommended by Henseler et al. (2015). A plausible explanation for this could reside in the inability of respondents to discriminate against the differences among the four components of transformational leadership variables, especially idealised influence and intellectual stimulation. Hence, we may say that the data suffers from the higher limit of discriminant validity due to having passed the Fornell-Larcker criterion, but not HTMT0.90 (Vorhees, Brady, Calantone, \& Ramirez, 2016).

Table 3. The Heterotrait Monotrait ratio of correlation (HTMT) criterion

\begin{tabular}{|l|l|l|l|l|l|l|l|}
\hline \multicolumn{1}{|c|}{ Variable } & \multicolumn{1}{|c|}{ EB } & \multicolumn{1}{c|}{ II } & \multicolumn{1}{|c|}{ IC } & \multicolumn{1}{|c|}{ IM } & \multicolumn{1}{c|}{ IS } & KS & PE \\
\hline EB & & & & & & & \\
\hline II & 0.498 & & & & & & \\
\hline IC & 0.683 & 0.748 & & & & & \\
\hline IM & 0.551 & $\mathbf{0 . 9 2 8}$ & 0.816 & & & & \\
\hline IS & 0.663 & 0.828 & $\mathbf{0 . 9 9 2}$ & $\mathbf{0 . 9 0 5}$ & & & \\
\hline KS & 0.663 & 0.363 & 0.599 & 0.41 & 0.597 & & \\
\hline PE & 0.641 & 0.476 & 0.494 & 0.491 & 0.476 & 0.519 & \\
\hline
\end{tabular}

Abbreviation: EB=Entrepreneurial behaviour, II= Idealised influence, IC= Individualised consideration, IM= Inspirational motivation, IS= Intellectual stimulation, $\mathrm{KS}=$ Knowledge sharing, $\mathrm{PE}=$ Psychological empowerment

Source: own study.

\section{Structural model}

A bootstrapping procedure was conducted with 500 samples (Hair et al., 2014). Analysis from the structural model shows that there are six supported hypotheses $(\mathrm{H} 2, \mathrm{H} 4, \mathrm{H} 6, \mathrm{H} 9, \mathrm{H} 10$, and $\mathrm{H} 11)$, with one partially supported ( $\mathrm{H} 8$ ). All the supported hypotheses achieved a t-value of at least 1.645 , while the partly supported hypothesis $\mathrm{H} 8$ showed only a marginal $\mathrm{t}$-value, close to the significant threshold. For the explained variance of the endogenous variable of knowledge sharing and entrepreneurial behaviour, both have a considerable $\mathrm{R}^{2}$ value of $36.7 \%$ and $54.7 \%$, respectively.

As for the effect size of $\mathrm{f}^{2}$, all the supported hypotheses achieved a minimal effect size of 0.02 , which can be concluded to have a small effect on the variable existence (Peng \& Lai, 2012). Effect size depends on the threshold suggested at $0.02,0.15$, and 0.35 , which depicted small, medium, and large effects, respectively (Cohen, 1988). All the non-supported paths show that the effect size is less than 0.02 in $\mathrm{H} 5$ and $\mathrm{H} 7$, which indicated the non-existence of effects with zero $\mathrm{f}^{2}$ value. Except for $\mathrm{H} 8$ (partially supported), the effect size recorded the value of 0.013 , slightly lower than the required 0.02 . This hypothesis was justified by the value of its $t$-value, which barely passed the significance level. 
As for the explained variance of $\mathrm{R}^{2}$, the two endogenous variables had $36.7 \%$ and $54.7 \%$ explained variance, respectively. As recommended, the value of $R^{2}$ should be within the value of $0.67,0.33$, and 0.19 , which can be considered as substantial, moderate, and weak, respectively. Hence, the value of $36.7 \%$ and $54.7 \%$ were deemed to be both moderate. Figure 2 below depicts the structural path, while Table 4 shows the results of hypotheses testing based on the structural analysis.

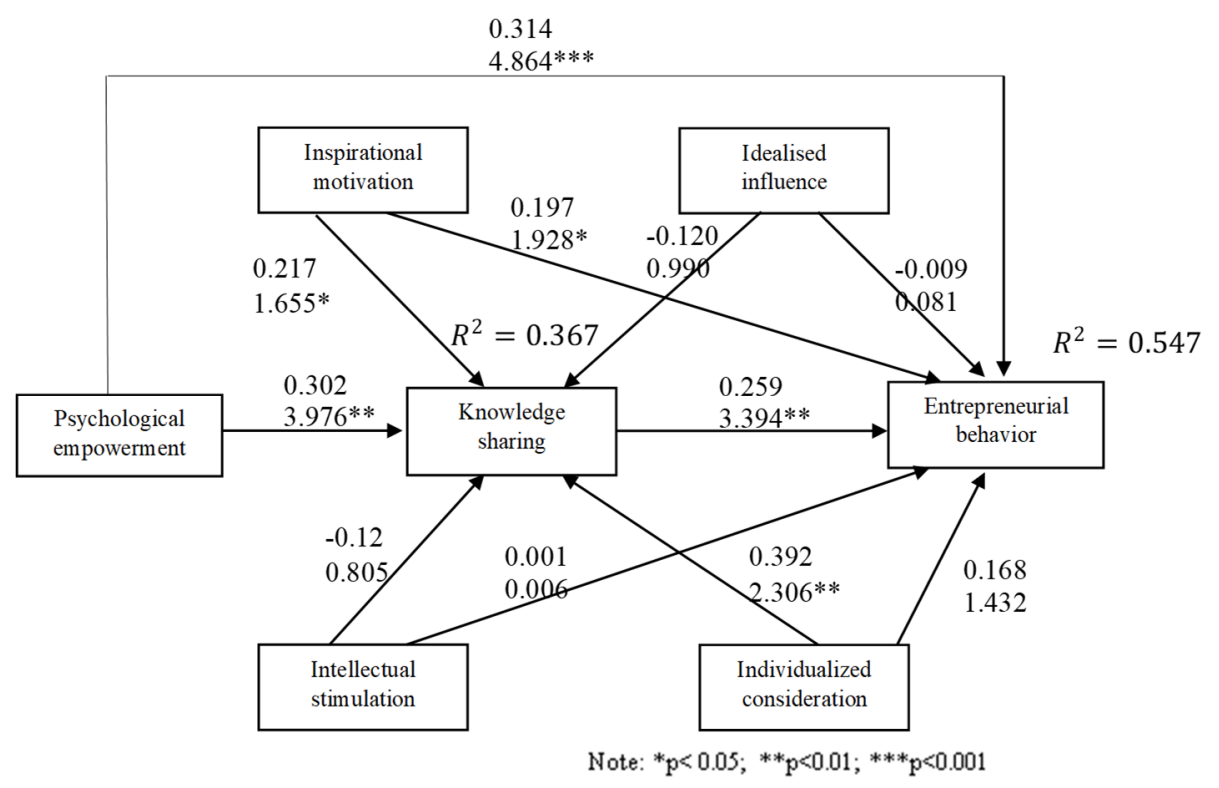

Figure 2. Results of structural analysis Source: own elaboration.

Table 4. Results of the structural model

\begin{tabular}{|l|c|c|c|c|c|}
\hline \multicolumn{1}{|c|}{ Hypothesis } & $\beta$-value & $\mathbf{f}^{2}$ value & t-value & P-value & Decision \\
\hline H1: Idealised influence $\rightarrow$ knowledge sharing & -0.12 & 0.008 & 0.99 & 0.323 & Not supported \\
\hline H2: Idealised influence $\rightarrow$ Entrepreneurial behaviour & -0.009 & 0 & 0.081 & 0.935 & Not supported \\
\hline H3: Inspirational motivation $\rightarrow$ Knowledge Sharing & 0.217 & 0.023 & 1.655 & 0.098 & Supported \\
\hline H4: Inspirational motivation $\rightarrow$ Entrepreneurial behaviour & 0.197 & 0.026 & 1.928 & 0.054 & Supported \\
\hline H5: Intellectual stimulation $\rightarrow$ Knowledge sharing & -0.12 & 0.006 & 0.805 & 0.421 & Not supported \\
\hline H6: Intellectual stimulation $\rightarrow$ Entrepreneurial behaviour & 0.001 & 0 & 0.006 & 0.995 & Not supported \\
\hline H7: Individualised consideration $\rightarrow$ Knowledge Sharing & 0.392 & 0.055 & 2.306 & 0.022 & Supported \\
\hline H8: Individualised consideration $\rightarrow$ Entrepreneurial behaviour & 0.168 & 0.013 & 1.432 & 0.153 & Partially supported \\
\hline H9: Psychological Empowerment $\rightarrow$ Knowledge sharing & 0.302 & 0.112 & 3.976 & 0 & Supported \\
\hline H10: Knowledge sharing $\rightarrow$ Entrepreneurial behaviour & 0.259 & 0.094 & 3.394 & 0.001 & Supported \\
\hline H11: Psychological Empowerment $\rightarrow$ Entrepreneurial behaviour & 0.314 & 0.152 & 4.864 & 0 & Supported \\
\hline
\end{tabular}
Source: own study.

\section{Discussion}

Based on the findings, we observed that six hypotheses were supported and one partially supported. The supported hypotheses are $\mathrm{H} 2, \mathrm{H} 4, \mathrm{H} 6, \mathrm{H} 9, \mathrm{H} 10$, and $\mathrm{H} 11$, while partly supported is $\mathrm{H} 8$. All the supported hypotheses have path coefficient, a $\beta$-value of at least 0.197 , which is considered to have a substantial path strength towards its endogenous variable. The following discussion consider each of the variables tested in this study.

Idealised influence. Both idealised influence relationship to knowledge sharing and psychological empowerment were found to be insignificant with a $\beta$-value of -0.12 and -0.009 , respectively. However, the relationship between idealised influence and knowledge sharing does have a degree of correlation but does not pass the threshold value of a significant level. Thus, we may deduce that the Malaysian population does not perceive the charismatic leader as crucial in sharing knowledge and 
impacting entrepreneurial activities. The emotional bond created by idealised influence leaders is only perceived as external factors that make followers feeling contented with their work rather than having an impact on their knowledge sharing and entrepreneurial behaviour (Giltinane, 2013). Followers will not be affected by how leaders lay out plans on achieving goals, as these leaders are focused in their goals, oriented in executing plans, and persistent in their decision making as suggested by Gabel (2012). This sample of students seems to contradict the influence created by such leaders and hence, can be concluded that charisma and emotional attraction have no empirical evidence influencing follower's knowledge sharing and entrepreneurial behaviour.

Inspirational motivation. For the second domain of transformational leadership, the analysis discovered that inspirational motivation has a significant impact on knowledge sharing with a $\beta$-value of 0.217 and a t-value of 1.655. Similarly, entrepreneurial behaviour had a significant impact with a $\beta$ value of 0.197 and a t-value of 1.928 . This is congruent with other studies that found the inspirational motivation to have a positive and significant effect on knowledge sharing (Han et al., 2016). Moreover, followers are more motivated to exhibit positive behaviours as this study suggests (knowledge sharing) when their leaders serve as inspirers. Inspiration from leaders makes followers become more enthusiastic for achieving team directive goals through knowledge sharing. Entrepreneurial activities are considered to be an activity that makes people move outside their comfort zones. Having leaders that can inspiringly motivate makes individuals abandon shyness to participate in entrepreneurial activities, and we should remember that shyness is prevalent in the Malaysian context (Long et al., 2014; Mittal \& Dhar, 2015; Deinert et al., 2015; Fauzi et al., 2018a).

Intellectual stimulation. Leaders - meaning CEOs of companies that can stimulate subordinates can induce employee's meaningfulness on their work (Peng et al., 2016). For this study sample we found that intellectual stimulation does not have a significant impact on knowledge sharing and entrepreneurial behaviour with both $\beta$-value of -0.12 and 0.001 , respectively. The previous study shows that intellectual stimulation does affect knowledge sharing (Al-Husseini \& Elbeltagi, 2018). Thus, we may surmise that leaders who empower follower's intellect would induce creative ways in solving problems and discussing work issues openly (Deinert et al., 2015; Carreiro \& Oliveira, 2019). The insignificance of this study can be attributed to the fact that students do not require as much intellectual stimulation from other peers. Moreover, they might not value leaders in their team that have control or absolute power in determining the consequences of their entrepreneurial activities.

Individualised consideration. Individualised consideration was found to be significant for knowledge sharing with a $\beta$-value of 0.392 and a t-value of 2.306. Meanwhile, individualised consideration is found to partially support entrepreneurial behaviour. Leaders who mark high in individualised consideration would form a dyadic relationship with each follower individually (Herman \& Chiu, 2014). The leaders understand followers based on their needs and requirements. Students in this sample would share their knowledge when leaders focus mainly on the individual. An individual would feel more appreciated and be disposed to share their knowledge as they feel they are unique to their leaders (Martin, 2017; Chen et al., 2018). Meanwhile, entrepreneurial behaviour emerges as partially significant in this context due to the nature of entrepreneurial activity itself that would encourage them to participate in such activities.

Psychological empowerment. Psychological empowerment was shown to have a significant relationship to student's knowledge sharing with a $\beta$-value of 0.302 and a t-value of 3.976 , which indicates a significance below the 0.01 level. The effect size of psychological empowerment also shows a strong effect with the value of 0.112. This supports the study by Houghton et al. (2015) who considered individual knowledge sharing based on the view "sharing is caring." Individuals who are empowered would develop a sense of confidence and build a trusting relationship; this will lead them to share their knowledge, in this case, entrepreneurial knowledge. Some entrepreneurial knowledge is considered to be tacit in its nature, as tacit knowledge is valuable to the beholder especially in entrepreneurial activities. Hence, with appropriate empowerment, one would have no qualm to share their tacit knowledge that is perceived as valuable and profitable.

On the other hand, the relationship of psychological empowerment on entrepreneurial behaviour was observed at the $\beta$-value of 0.314 and t-value of 4.864 , indicating a much stronger correlation. The 
effect size was recorded at the value of 0.152 , thus indicating a strong effect. This study is consistent with previous studies that found a significant relationship between the two variables (Afsar et al., 2016). Students will be more engaged in entrepreneurial behaviour when their leaders empower them. The meaning and impact a leader can have on an individual develops the latter's competence, resilience, and responsibility (Kang et al., 2017; Houghton et al., 2015; Jha, 2014).

Knowledge sharing. The explained variance of R2 by psychological empowerment and the four components of transformational leadership on knowledge sharing value is $36.7 \%$, which shows a substantial correlation from its antecedents. The relationship with entrepreneurial behaviour had a $\beta$ value of 0.259 and a t-value of 3.394 that supported the hypothesis. An effect size of 0.094 shows the medium effect of knowledge sharing on the model. Student's knowledge sharing behaviour indicates their willingness to participate in entrepreneurship activities. As undergraduate students have limited resources and are confined to campus communities, they must utilise every source of information and specific knowledge on what to do to generate income and ensure a smooth monetary inflow. Considering this, students who are active and viable in knowledge sharing would take the initiative to engage in entrepreneurial activities. In this regard, knowledge sharing shows to be a decisive factor for individual entrepreneurial activities as evidenced by other empirical findings (Hormiga et al., 2016; De Clercq et al., 2013; Castro et al., 2019).

Entrepreneurial behaviour. As the dependent variable in this study, students' entrepreneurial behaviour is seen as the most sought-after skill required among future generations. The explained variance of R2 was found to be $54.7 \%$, indicating a high predictive power explained by the precedent variable. With seven hypotheses designed as seven exogenous variables on entrepreneurial behaviour, four were supported, one was partially supported, and two were rejected. This reveals that several variables are pivotal in ensuring that entrepreneurial behaviour among students is nurtured. For the transformational leadership domain, only inspirational motivation was significant in entrepreneurial behaviour, which suggests that students are only inspired to engage in entrepreneurial activities when leaders are seen as motivating individuals.

\section{CONCLUSIONS}

Students require effort from transformation leaders, especially in the context of Malaysia, where students embrace typical Asian characteristics, namely shyness, reticence, and modesty (Fauzi, Tan, Thurasamy, \& Ojo, 2019a). Entrepreneurship activities require individuals to move outside their comfort zone and try new things. Therefore, to encourage individuals - especially in higher education institutions - internal motivation portrayed by psychological empowerment should be infused within group work. From this self-belief and significant impact of transformational leadership components, an individual would willingly share their knowledge and information on the entrepreneurial activities in which they are engaged. Next, the individual would be more inclined towards positive entrepreneurial behaviour.

Our study revealed that two out of four transformational leaderships show significant relationship (inspirational motivation and individualised consideration) to knowledge sharing and entrepreneurial behaviour. On the other hand, psychological empowerment emerged as a significant factor for knowledge sharing and entrepreneurial behaviour. Moreover, knowledge sharing is a significant factor in entrepreneurial behaviour. The result would provide an in-depth understanding that would enable the government and curriculum developers to infuse these factors in integrating entrepreneurial subjects in higher education.

As for the limitations of this study, we applied a cross-sectional approach, which only captures the behaviour of respondents within a certain period of time. While longitudinal studies are preferred, cross-sectional studies in higher education are sufficient as students' behaviour does not change drastically over the period of their undergraduate studies (Fauzi et al., 2019b). On top of that, the same cohort of students registered in the same year reflects what they are expected to be at the time of their graduation. Moreover, all respondents were engineering students. Studying stu- 
dents only from the field of engineering would provide information leaning towards technically inclined respondents, for whom entrepreneurship requires more openness and good soft skills in communicating with people. Our study might have engendered an alternative result if we considered students from other majors. Nonetheless, this study provides an understanding of how engineering students perceive entrepreneurship to be integrated into their engineering curriculum. Future studies could assess students from other technical or analytical background such as medical and health field, actuarial science and architecture. Different technical background may end up differently due to the nature of the major.

\section{REFERENCES}

Afsar, B., Badir, Y.F., Saeed, B.B., \& Hafeez, S. (2017). Transformational and transactional leadership and employee's entrepreneurial behavior in knowledge-intensive industries. The International Journal of Human Resource Management, 28(2), 307-332. https://doi.org/10.1080/09585192.2016.1244893

Akhavan, P., Hosseini, S.M., Abbasi, M., \& Manteghi, M. (2015). Knowledge-sharing determinants, behaviours, and innovative work behaviours: an integrated theoretical view and empirical examination. Aslib Journal of Information Management, 67(5), 562-591. https://doi.org/10.1108/AJIM-02-2015-0018

Al-Husseini, S., \& Elbeltagi, I. (2018). Evaluating the effect of transformational leadership on knowledge sharing using structural equation modelling: the case of Iraqi higher education. International Journal of Leadership in Education, 21(4), 506-517. https://doi.org/10.1080/13603124.2016.1142119

Avolio, B.J., Bass, B.M., \& Jung, D.I. (1999). Re-examining the components of transformational and transactional leadership using the multifactor leadership. Journal of Occupational and Organizational Psychology, 72(4), 441-462.

Barbuto Jr, J.E. (2005). Motivation and transactional, charismatic, and transformational leadership: A test of antecedents. Journal of Leadership \& Organizational Studies, 11(4), 26-40.

Bass, B.M. (1985). Leadership and performance beyond expectations. New York: The Free Press.

Bass, B.M., \& Avolio, B.J. (1995). MLQ multifactor leadership questionnaire. Redwood City, CA: Mind Garden.

Bass, B.M., \& Riggio, R.E. (2006). Transformational leadership. New Jersey: Lawrence Erlbaum Associates.

Baytok, A., Kurt, M., \& Zorlu, Ö. (2014). The role of transformational leader on knowledge sharing practices: a study about international hotel chains. European Journal of Business and Management, 6(7), 46-61.

Carreiro, H., \& Oliveira, T. (2019). Impact of transformational leadership on the diffusion of innovation in firms: Application to mobile cloud computing. Computers in Industry, 107, 104-113. https://doi.org/10.1016/j.compind.2019.02.006

Castro, I.J.D., Nagano, M.S., \& Ribeiro, S.X. (2018). Elements that influence knowledge sharing in the universityindustry-government collaboration: Case studies in Brazil. Revista de Gestão, 26(1), 61-72. https://doi.org/10.1108/REGE-04-2018-0061

Cicolini, G., Comparcini, D., \& Simonetti, V. (2014). Workplace empowerment and nurses' job satisfaction: a systematic literature review. Journal of Nursing Management, 22(7), 855-871. https://doi.org/10.1111/jonm.12028

Chen, Z.J., Davison, R.M., Mao, J.Y., \& Wang, Z.H. (2018). When and how authoritarian leadership and leader renqing orientation influence tacit knowledge sharing intentions. Information \& Management, 55(7), 840849. https://doi.org/10.1016/j.im.2018.03.011

Cohen, J. (1988). Statistical power analysis for the behavioural sciences. Hillside, NJ: L. Erlbaum Associates.

Coun, M.M., Peters, P.C., \& Blomme, R.R. (2018). 'Let's share!'The mediating role of employees' self-determination in the relationship between transformational and shared leadership and perceived knowledge sharing among peers. European Management Journal, 37(4), 481-491. https://doi.org/10.1016/j.emj.2018.12.001

De Clercq, D., Dimov, D., \& Thongpapanl, N. (2013). Organizational social capital, formalization, and internal knowledge sharing in entrepreneurial orientation formation. Entrepreneurship Theory and Practice, 37(3), 505-537. https://doi.org/10.1111/etap.12021

Deinert, A., Homan, A.C., Boer, D., Voelpel, S.C., \& Gutermann, D. (2015). Transformational leadership sub-dimensions and their link to leaders' personality and performance. The Leadership Quarterly, 26(6), 1095-1120. https://doi.org/10.1016/j.leaqua.2015.08.001 
Dijkstra, T.K., \& Henseler, J. (2015). Consistent partial least squares path modeling. MIS Quarterly, 39(2), 297316. Retrieved from http://www.composite-modeling.com/app/download/10518096224/2015_MISQ_ Dijkstra_Henseler.pdf?t=1420483626 on January 20, 2020.

Farrukh, M., Lee, J.W.C., \& Shahzad, I.A. (2019). Intrapreneurial behaviour in higher education institutes of Pakistan: The role of leadership styles and psychological empowerment. Journal of Applied Research in Higher Education, 11(2), 273-294. https://doi.org/10.1108/JARHE-05-2018-0084

Fauzi, M.A., Nya-Ling, C.T., Thurasamy, R., \& Ojo, A.O. (2018a). An integrative model of knowledge sharing in Malaysian higher learning Institute. Kybernetes, 47(5), 1031-1052. https://doi.org/10.1108/K-10-2017-0388

Fauzi, M.A., Tan, C.N.L., \& Ramayah, T. (2018b). Knowledge sharing intention at Malaysian higher learning institutions: The academics' viewpoint. Knowledge Management \& E-Learning: An International Journal, 10(2), 163-176.

Fauzi, M.A., Nya-Ling, C.T., Thurasamy, R., \& Ojo, A.O. (2019a). Knowledge sharing: Role of academics towards research productivity in higher learning institution. VINE Journal of Information and Knowledge Management Systems, 49(1), 136-159.

Fauzi, M.A, Tan Nya-Ling, C., Thurasamy, R., Oluwaseyi Ojo, A., \& Shogar, I. (2019b). Muslim academics' knowledge sharing in Malaysian higher learning institutions. Journal of Islamic Marketing, 10(2), 378-393.

Fauzi, M.A., Tan, C.N.L., Thurasamy, R., \& Ojo, A.O. (2019c). Evaluating academics' knowledge sharing intentions in Malaysian public universities. Malaysian Journal of Library \& Information Science, 24(1), 123-143.

Gabel, S. (2012). Power, leadership and transformation: The doctor's potential for influence. Medical Education, 46(12), 1152-1160. https://doi.org/10.1111/medu.12036

Giltinane, C.L. (2013). Leadership styles and theories. Nursing Standard, 27(41). 35-9. https://doi.org/10.7748/ns2013.06.27.41.35.e7565

Hair, J.F., Hult, G.T., Ringle, C.M., \& Sarstedt, M. (2014). A primer on partial least squares structural equation modeling (PLS-SEM). Sage Publications.

Hair Jr, J.F., Matthews, L.M., Matthews, R.L., \& Sarstedt, M. (2017). PLS-SEM or CB-SEM: updated guidelines on which method to use. International Journal of Multivariate Data Analysis, 1(2), 107-123.

Han, S.H., Seo, G., Yoon, SW., \& Yoon, D.Y. (2016). Transformational leadership and knowledge sharing: Mediating roles of employee's empowerment, commitment, and citizenship behaviours. Journal of Workplace Learning, 28(3), 130-149. retrieved from https://www.deepdyve.com/lp/emerald-publishing/transformational-leadership-and-knowledge-sharing-MUewvgaVcR on August 20, 2020.

Henseler, J., Ringle, C.M., \& Sarstedt, M. (2015). A new criterion for assessing discriminant validity in variancebased structural equation modeling. Journal of the Academy of Marketing Science, 43(1), 115-135. https://doi.org/10.1007/s11747-014-0403-8

Hormiga, E., de Saá-Pérez, P., Díaz-Díaz, N.L., Ballesteros-Rodríguez, J.L., \& Aguiar-Diaz, I. (2017). The influence of entrepreneurial orientation on the performance of academic research groups: the mediating role of knowledge sharing. The Journal of Technology Transfer, 42(1), 10-32. https://doi.org/10.1007/s10961-015-9463-2

Houghton, J.D., Pearce, C.L., Manz, C.C., Courtright, S., \& Stewart, G.L. (2015). Sharing is caring: Toward a model of proactive caring through shared leadership. Human Resource Management Review, 25(3), 313-327. https://doi.org/10.1016/j.hrmr.2014.12.001

Jauhari, H., Singh, S., \& Kumar, M. (2017). How does transformational leadership influence proactive customer service behaviour of frontline service employees? Examining the mediating roles of psychological empowerment and affective commitment. Journal of Enterprise Information Management, 30(1), 30-48. https://doi.org/10.1016/j.hrmr.2014.12.001

Jha, S. (2014). Transformational leadership and psychological empowerment: Determinants of organizational citizenship behaviour. South Asian Journal of Global Business Research, 3(1), 18-35. https://doi.org/10.1108/SAJGBR-04-2012-0036

Kang, Y.J., Lee, J.Y., \& Kim, H.W. (2017). A psychological empowerment approach to online knowledge sharing. Computers in Human Behavior, 74, 175-187. https://doi.org/10.1016/j.chb.2017.04.039

Lan, X.M., \& Chong, W.Y. (2015). The mediating role of psychological empowerment between transformational leadership and employee work attitudes. Procedia-Social and Behavioural Sciences, 172, 184-191. https://doi.org/10.1016/j.sbspro.2015.01.353 
Li, C., Zhao, H., \& Begley, T.M. (2015). Transformational leadership dimensions and employee creativity in China: A cross-level analysis. Journal of Business Research, 68(6), 1149-1156. https://doi.org/10.1016/j.jbusres.2014.11.009

Liu, Y., \& DeFrank, R.S. (2013). Self-interest and knowledge-sharing intentions: The impacts of transformational leadership climate and HR practices. The International Journal of Human Resource Management, 24(6), 1151-1164. https://doi.org/10.1080/09585192.2012.709186

Long, C.S., Yusof, W.M.M., Kowang, T.O., \& Heng, L.H. (2014). The impact of transformational leadership style on job satisfaction. World Applied Sciences Journal, 29(1), 117-124. https://doi.org/10.5829/idosi.wasj.2014.29.01.1521

Martin, J. (2017). Personal relationships and professional results: The positive impact of transformational leaders on academic librarians. The Journal of Academic Librarianship, 43(2), 108-115. https://doi.org/10.1016/J.ACALIB.2017.01.012

Martin, B.C., McNally, J.J., \& Kay, M.J. (2013). Examining the formation of human capital in entrepreneurship: A meta-analysis of entrepreneurship education outcomes. Journal of Business Venturing, 28(2), 211-224. https://doi.org/10.1016/j.jbusvent.2012.03.002

Masa'deh, R.E., Obeidat, B.Y., \& Tarhini, A. (2016). A Jordanian empirical study of the associations among transformational leadership, transactional leadership, knowledge sharing, job performance, and firm performance: A structural equation modelling approach. Journal of Management Development, 35(5), 681-705. https://doi.org/10.1108/JMD-09-2015-0134

Mittal, S., \& Dhar, R.L. (2015). Transformational leadership and employee creativity: mediating role of creative self-efficacy and moderating role of knowledge sharing. Management Decision, 53(5), 894-910. https://doi.org/10.1108/MD-07-2014-0464

Nam Nguyen, H., \& Mohamed, S. (2011). Leadership behaviours, organizational culture and knowledge management practices: An empirical investigation. Journal of Management Development, 30(2), 206-221. https://doi.org/10.1108/02621711111105786

Peng, D.X., \& Lai, F. (2012). Using partial least squares in operations management research: A practical guideline and summary of past research. Journal of Operations Management, 30(6), 467-480. https://doi.org/10.1016/j.jom.2012.06.002

Peng, A.C., Lin, H.E., Schaubroeck, J., McDonough III, E.F., Hu, B., \& Zhang, A. (2016). CEO intellectual stimulation and employee work meaningfulness: The moderating role of organizational context. Group \& Organization Management, 41(2), 203-231.

Pieterse, A.N., Van Knippenberg, D., Schippers, M., \& Stam, D. (2010). Transformational and transactional leadership and innovative behavior: The moderating role of psychological empowerment. Journal of Organizational Behavior, 31(4), 609-623. https://doi.org/10.1002/job.650

Pittaway, L., \& Cope, J. (2007). Entrepreneurship education: A systematic review of the evidence. International Small Business Journal, 25(5), 479-510. https://doi.org/10.1177/0266242607080656

Salamzadeh, A., Farjadian, A.A., Amirabadi, M., \& Modarresi, M. (2014). Entrepreneurial characteristics: insights from undergraduate students in Iran. International Journal of Entrepreneurship and Small Business, 21(2), 165-182. https://doi.org/10.1504/IJESB.2014.059471

Salamzadeh, A. (2020). What constitutes a theoretical contribution?. Journal of Organizational Culture, Communications and Conflicts, 24(1), 1-2.

Seibert, S.E., Wang, G., \& Courtright, S.H. (2011). Antecedents and consequences of psychological and team empowerment in organizations: a meta-analytic review. Journal of Applied Psychology, 96(5), 981. https://doi.org/10.1037/a0022676

Spreitzer, G.M. (2008). Taking stock: A review of more than twenty years of research on empowerment at work. Handbook of Organizational Behaviour, 1, 54-72. https://doi.org/10.4135/9781849200448.n4

Spreitzer, G.M. (1995). Psychological empowerment in the workplace: Dimensions, measurement, and validation. Academy of Management Journal, 38, 1442-1465. https://doi.org/10.2307/256865

Sun, L.Y., Zhang, Z., Qi, J., \& Chen, Z.X. (2012). Empowerment and creativity: A cross-level investigation. The Leadership Quarterly, 23(1), 55-65. https://doi.org/10.1016/j.leaqua.2011.11.005

Tyssen, A.K., Wald, A., \& Spieth, P. (2014). The challenge of transactional and transformational leadership in projects. International Journal of Project Management, 32(3), 365-375. https://doi.org/10.1016/j.ijproman.2013.05.010 
Voorhees, C.M., Brady, M.K., Calantone, R., \& Ramirez, E. (2016). Discriminant validity testing in marketing: an analysis, causes for concern, and proposed remedies. Journal of the Academy of Marketing Science, 44(1), 119-134. https://doi.org/10.1007/s11747-015-0455-4

Wang, H., Tsui, A.S., \& Xin, K.R. (2011). CEO leadership behaviours, organizational performance, and employees' attitudes. The Leadership Quarterly, 22(1), 92-105. https://doi.org/10.1016/j.leaqua.2010.12.009

Wartiovaara, M., Lahti, T., \& Wincent, J. (2018). The role of inspiration in entrepreneurship: Theory and the future research agenda. Journal of Business Research, 101, 548-554. https://doi.org/10.1016/j.jbusres.2018.11.035

Zhu, W., Sosik, J.J., Riggio, R.E., \& Yang, B. (2012). Relationships between transformational and active transactional leadership and followers' organizational identification: The role of psychological empowerment. Journal of Behavioural and Applied Management, 13(3), 186.

Zbierowski, P. (2016). Positive leadership and corporate entrepreneurship: theoretical considerations and research propositions. Entrepreneurial Business and Economics Review, 4(3), 73-84. https://doi.org/10.15678/EBER.2016.040306 


\section{Authors}

The contribution of co-authors is equal and can be expressed as at least $33.33 \%$ for each of the authors: Muhammad Ashraf Fauzi developed the theoretical framework and data collection. T. Martin prepared the literature review, while Kamalesh Ravesangar prepared the statistical calculations.

\section{Muhammad Ashraf Fauzi}

Muhammad Ashraf Fauzi is Senior Lecturer at the Faculty of Industrial Management, Universiti Malaysia Pahang. He completed his PhD at the Faculty of Management in 2018, Multimedia University. He has more than 10 years of academic experience, where he worked for nine years at the Centre for Foundation Studies, IIUM. His research interests include knowledge management, organisational behaviour, marketing, leadership, entrepreneurship, quality management, and project management. He published nearly 15 articles in top-tier journals. He holds Master's degree in Manufacturing System Engineering (2013, Universiti Putra Malaysia) and a Bachelor degree in Manufacturing Engineering (2010, International Islamic University Malaysia).

Correspondence to: Muhammad Ashraf Fauzi, PhD, Universiti Malaysia Pahang, Faculty of Industrial Management, Lebuhraya Tun Razak, 26300, Kuantan Pahang, Malaysia e-mail: ashrafauzi@ump.edu.my ORCID (1) http://orcid.org/0000-0003-2137-4602

\section{Tulasi Martin}

Tulasi Martin is a PhD candidate in the Faculty of Industrial Management, Universiti Malaysia Pahang.

Correspondence to: Tulasi Martion, Faculty of Industrial Management, Universiti Malaysia Pahang, Lebuhraya Tun Razak, 26300, Kuantan Pahang, Malaysia, email: asvinee86@gmail.com

ORCID (1) http://orcid.org/0000-0002-3365-8314

\section{Kamalesh Ravesangar}

Kamalesh Ravesangar is a Lecturer with over seven years of experience in teaching Certificate, Diploma, Degree, and MBA students from various social and cultural background at private colleges and universities. Moreover, Ravesangear has the total of three years of experiences in industries related to educational, manufacturing, recruitment, and engineering. A subject matter expert in human resource management, human resource development, management and organisational behavior studies, Ravesangar published articles and reviewed articles in online journal publications. He has excellent administrative, verbal communication, research, and written skills, along with creative and effective teaching methods that develop stimulating learning environment. He holds a doctorate and a Master's degree in Organisational Behavior and Human Resource Management.

Correspondence to: Kamalesh Ravesangar PhD, Lecturer at Àlbukhary International University e-mail: anjalikha25@gmail.com

ORCID (1) http://orcid.org/0000-0003-3882-0103

\section{Acknowledgements and Financial Disclosure}

This work was funded by Universiti Malaysia Pahang under the Ministry of Higher Education Malaysia RACER/1/2019/SS03/UMP//1 (Grant no. RDU192619) and UMP Postgraduate Research Grant (PGRS) (Grant no. PGRS200309).

\section{Conflict of Interest}

The authors declare that the research was conducted in the absence of any commercial or financial relationships that could be construed as a potential conflict of interest.

\section{Copyright and License}

This article is published under the terms of the Creative Commons

Attribution - NoDerivs (CC BY-ND 4.0) License

http://creativecommons.org/licenses/by-nd/4.0/ 
